\title{
Efeito do tempo de descongelamento de grãos de pólen de mamoneira armazenados em diferentes temperaturas
}

\author{
Cristina Copstein Cuchiara ${ }^{1 *}$ \\ Sérgio Alessandro Machado Souza ${ }^{2}$ \\ Sergio Delmar dos Anjos e Silva ${ }^{3}$ \\ Vera Lucia Bobrowski ${ }^{1}$ \\ ${ }^{1}$ Universidade Federal de Pelotas, Instituto de Biologia \\ Departamento de Zoologia e Genética, Laboratório de Genética \\ Campus Universitário, s/n, Caixa Postal 354, CEP 96160-000, Capão do Leão - RS, Brasil \\ ${ }^{2}$ Universidade Estadual do Norte Fluminense Darcy Ribeiro \\ Laboratório de Melhoramento Genético Vegetal, Campos de Goytacazes - RJ, Brasil \\ ${ }^{3}$ Embrapa Clima Temperado, Pelotas - RS, Brasil \\ * Autor para correspondência \\ cccuchiara@hotmail.com
}

Submetido em 06/02/2012

Aceito para publicação em 26/06/2012

\section{Resumo}

O objetivo deste trabalho foi avaliar o efeito do tempo de descongelamento de grãos de pólen de cultivares de mamoneira submetidos a diferentes ambientes e períodos de armazenamento. Para isso, grãos de pólen foram mantidos em 4 ambientes: refrigerador $\left(4^{\circ} \mathrm{C}\right)$, freezer $\left(-18^{\circ} \mathrm{C}\right)$, ultrafreezer $\left(-72^{\circ} \mathrm{C}\right)$ e nitrogênio líquido $\left(-196^{\circ} \mathrm{C}\right)$ por 60 dias. Para avaliar a viabilidade foi realizada a germinação in vitro em três testes: 15,30 e 60 dias, nos quais os grãos de pólen germinados no intervalo de uma hora foram analisados até completar $6 \mathrm{~h}$ e após $24 \mathrm{~h}$. Em delineamento inteiramente casualizado foram analisados 100 grãos de pólen nas 6 repetições de cada tratamento. Para o cultivar IAC 80, tanto em 15 quanto em 30 dias de armazenamento em ultrafreezer, obteve-se em torno de $50 \%$ de grãos de pólen germinados necessitando de $5 \mathrm{~h}$ a $6 \mathrm{~h}$ de incubação para a retomada do metabolismo, respectivamente. Para o cultivar AL Guarany 2002, o ultrafreezer apresentou uma maior uniformidade técnica, porém, a melhor germinação foi alcançada na criopreservação. Aos 60 dias houve uma drástica redução na viabilidade em todos os ambientes. Dependendo da temperatura, pode haver necessidade de um maior tempo de descongelamento para a retomada das atividades fisiológicas.

Palavras-chave: Baixa temperatura; Conservação de pólen; Germinação in vitro; Ricinus communis; Tubo polínico

\section{Abstract}

Effect of the thawing time of castor bean pollen grains stored at different temperatures. This paper aimed at evaluating the effect of thawing time of pollen grains of castor bean cultivars undergoing different environmental conditions and storage periods. For this, pollen grains were maintained in four environments: refrigerator $\left(4^{\circ} \mathrm{C}\right)$, freezer $\left(-18^{\circ} \mathrm{C}\right)$, ultrafreezer $\left(-72^{\circ} \mathrm{C}\right)$, and liquid nitrogen $\left(-196^{\circ} \mathrm{C}\right)$ for 60 days. To evaluate viability, in vitro germination was carried out in three tests: 15,30 , and 60 days, in which the pollens grains 
germinated within an hour were analyzed up to $6 \mathrm{~h}$ and after $24 \mathrm{~h}$. In a completely randomized design, 100 pollen grains were analyzed in the 6 replications of each treatment. For the cultivar IAC 80, both after 15 and 30 days of storage in ultrafreezer, about $50 \%$ of pollen grains germinated required from $5 \mathrm{~h}$ to $6 \mathrm{~h}$ of incubation for the resumption of metabolism, respectively. For the cultivar AL Guarany 2002, ultrafreezer presented a higher degree of technical uniformity; however, the best germination was achieved through criopreservation. After 60 days, there was a dramatic decrease in the viability under all environmental conditions. Depending on the temperature, there may be a need for a larger thawing time for the resumption of physiological activities.

Key words: In vitro germination; Low temperature; Pollen conservation; Pollen tubes; Ricinus communis

\section{Introdução}

O Brasil, pela sua imensa extensão territorial associada às excelentes condições edafoclimáticas, é considerado um paraíso para a produção de biomassa para fins alimentares, químicos e energéticos. Devido a essas características, encontra-se em destaque o cultivo de mamoneira (Ricinus communis L.), uma oleaginosa considerada de grande importância socioeconômica, pois seu óleo, extraído pela prensagem das sementes, contém cerca de $90 \%$ de ácido graxo ricinoléico com uma ampla gama de utilização industrial (SAVY FILHO et al., 1999). Portanto, a conservação do germoplasma e o melhoramento genético desta espécie podem proporcionar uma melhor exploração destes recursos (BELTRÃO, 2003).

O armazenamento de pólen é um processo imprescindível quando se pretende realizar o cruzamento de espécies com períodos distintos de floração, transporte de material biológico e/ou preservação da variabilidade genética (GOMES et al., 2003; DANNER et al., 2011). Para que o mesmo tenha sucesso, fatores como a sua umidade, temperatura de armazenamento e tempo de descongelamento devem ser controlados. Estes estão diretamente relacionados ao metabolismo do pólen, à contaminação por microorganismos e a reativação dos processos metabólicos pós-conservação. A redução dessas atividades tende a aumentar a longevidade do pólen armazenado (SOUSA, 1990).

A temperatura está entre os mais importantes fatores ambientais que afetam os processos reprodutivos das plantas, tais como a germinação do pólen, crescimento do tubo polínico e frutificação (KAKANI et al., 2005), e tem também um efeito sobre o desempenho do pólen, tanto sobre a germinação quanto sobre o crescimento do tubo polínico de diferentes espécies, incluindo a mamoneira (ACAR; KAKANI, 2010).

O método de armazenamento a longo prazo mais promissor descrito na literatura é em nitrogênio líquido $\left(-196^{\circ} \mathrm{C}\right)$, onde metabolismo do pólen reduzse a praticamente zero, permitindo, teoricamente, a manutenção de sua viabilidade por um período indefinido (KARTHA, 1985). Os outros métodos de conservação somente adiam a deterioração por um período de tempo determinado e específico, de acordo com o material e a espécie em questão. Por isso, metodologias referentes a estas técnicas devem ser desenvolvidas, visto que cada espécie se porta diferentemente frente aos referidos processos, o que pode comprometer a viabilidade do pólen (SOUSA et al., 2010).

Com a finalidade de identificar o intervalo de tempo necessário para a reativação dos processos metabólicos após o armazenamento de material biológico, o objetivo do trabalho foi avaliar o efeito do tempo de descongelamento de grãos de pólen de cultivares de mamoneira (Ricinus communis L.) submetidas a diferentes ambientes e períodos de armazenamento à baixa temperatura.

\section{Material e Métodos}

O trabalho foi realizado no Laboratório de Genética do Departamento de Zoologia e Genética da Universidade Federal de Pelotas, UFPel. Foram coletadas inflorescências de duas variedades de mamoneira: IAC 80 e AL Guarany 2002, da Embrapa Clima Temperado - CPACT, localizado no município de Pelotas-RS, na latitude $31^{\circ} 41^{\prime} \mathrm{S}$ e longitude $52^{\circ} 21^{\prime} \mathrm{W}$ e de altitude $60 \mathrm{~m}$.

As amostras das duas variedades de mamoneira foram coletadas de inflorescências, levadas e mantidas 
no laboratório em água destilada à temperatura ambiente até a antese e retirada dos grãos de pólen. Estes foram acondicionados em tubo tipo eppendorf e criotubos para armazenamento, sendo retirada uma amostra para análise de viabilidade inicial onde se observou 48 e $37 \%$ de germinação in vitro para as cvs. IAC 80 e AL Guarany 2002, respectivamente.

Os tratamentos de conservação utilizados neste experimento foram nitrogênio líquido $\left(-196^{\circ} \mathrm{C}\right)$; ultrafreezer $\left(-72^{\circ} \mathrm{C}\right)$; freezer $\left(-18^{\circ} \mathrm{C}\right)$ e refrigerador $\left(4^{\circ} \mathrm{C}\right)$ durante 15,30 e 60 dias. A avaliação do intervalo de tempo de descongelamento necessário para a reativação dos processos metabólicos consistiu na análise da viabilidade polínica pelo teste de germinação in vitro de grãos de pólen armazenados.

A avaliação da germinação in vitro foi realizada utilizando meio de cultura constituído de $10 \mathrm{~g}$. $\mathrm{L}^{-1}$ de ágar e $100 \mathrm{~g} . \mathrm{L}^{-1} \mathrm{de}$ sacarose com $\mathrm{pH}$ ajustado para 6 (GOMES et al., 2003), onde foram aquecidos para total diluição do ágar. Ainda quente, o meio foi distribuído em placas de lâmina escavada de Kline com doze poros. O pólen foi polvilhado sobre o meio frio, com o auxílio de um pincel. As placas foram colocadas em placas de Petri com fundo coberto por papel Germitest umedecido (simulando uma câmara úmida), e levadas para incubação em câmara de germinação tipo B.O.D com temperatura controlada de $20^{\circ} \mathrm{C}$.

A avaliação foi realizada aos 15,30 e 60 dias de armazenamento nos diferentes ambientes. A técnica utilizada para avaliação constou da retirada dos grãos de pólen dos ambientes, dispersão dos mesmos em meio de cultivo, incubação das placas a $20^{\circ} \mathrm{C}$ e contagens de grãos de pólen germinados no intervalo de hora em hora até completar $6 \mathrm{~h}$ e após $24 \mathrm{~h}$ da retirada do ambiente de armazenamento, por meio da técnica de varredura com auxílio de microscópio óptico em aumento de 40x. Segundo Pasqual et al. (1982), foram considerados como germinados os polens que apresentaram tubo polínico de comprimento igual ou superior ao diâmetro do próprio pólen, totalizando 100 grãos de polens/ cavidade da placa. Cada cavidade foi considerada uma repetição e utilizada seis repetições por tratamento, em delineamento inteiramente casualizado.
Os resultados obtidos foram submetidos à análise de variância e as médias foram comparadas utilizado o teste de Duncan ( $\alpha=1 \%)$, com auxilio do programa estatístico SANEST (ZONTA; MACHADO, 1984). Os dados, expressos em porcentagem, foram transformados segundo arco seno de $(\mathrm{X} / 100)^{1 / 2}$, onde $\mathrm{X}$ representa $\mathrm{o}$ valor percentual obtido para cada variável. Como forma de desdobrar os efeitos da interação dos fatores efetuouse a análise de regressão polinomial, sendo representados na forma de figuras individuais para cada variedade de mamoneira e ambiente de armazenamento em baixas temperaturas.

\section{Resultados e Discussão}

Observou-se diferença estatística altamente significativa na interação dos fatores estudados $(\mathrm{p}<0,01)$, nos experimentos realizados aos 15 e 30 dias para as cvs. IAC 80 e AL Guarany 2002 (Tabela 1). Já o experimento realizado aos 60 dias de conservação mostrou diferença estatística significativa somente para o fator ambiente de armazenamento $(\mathrm{p}<0,05)$.

Com base em estudos realizados em diferentes espécies, evidenciou-se que dependendo do ambiente e da temperatura utilizada para conservação de pólen ocorreu a necessidade de um tempo maior de descongelamento para a retomada das atividades metabólicas, ou seja, cada espécie e a condição em que ela está submetida determina o tempo de incubação necessário para que haja germinação in vitro (SANTOS, 2000).

O número de grãos de pólen germinados não demonstrou efeitos significativos aos 15 e 30 dias de conservação em refrigerador (Figura 1A). Foi constatada uma porcentagem inferior a 3\% com o aumento do tempo de descongelamento, porém apresentou um leve aumento no porcentual de germinação até $3 \mathrm{~h}$ de reativação do metabolismo (3\%) aos 15 dias de experimento e, aos 30 dias de experimento, o número de grãos de pólen germinados aumentou $(2,45 \%)$ até $6 \mathrm{~h}$ de descongelamento e decaiu após esse período. Esses resultados não concordam com trabalhos de conservação de amendoeira (GOMEZ et al., 2000) e Pinus radiata (SIREGAR; SWEET, 2000) que mantiveram o pólen armazenado em refrigerador por vários meses, embora 
TABELA 1: Resumo da análise de variância para a variável grãos de pólen germinados de mamoneira cv. IAC 80 e AL Guarany 2002 submetidas a diferentes ambientes de armazenamento a baixas temperaturas e horas de descongelamento. Pelotas. UFPel, 2009.

\begin{tabular}{|c|c|c|c|c|}
\hline \multicolumn{5}{|c|}{ IAC 80} \\
\hline \multirow{3}{*}{ Causas da Variação } & \multirow{3}{*}{ GL } & \multicolumn{3}{|c|}{ Quadrado Médio } \\
\hline & & \multicolumn{3}{|c|}{ Germinação (\%) } \\
\hline & & 15 dias & 30 dias & 60 dias \\
\hline Ambiente & 3 & $13525,472 * *$ & $8579,176^{* *}$ & $0,176^{*}$ \\
\hline Horas & 6 & $587,684^{* *}$ & $1180,825 * *$ & $0,575 \mathrm{~ns}$ \\
\hline Ambiente $\mathrm{x}$ Horas & 18 & $160,372 * *$ & $187,801 * *$ & $0,059 \mathrm{~ns}$ \\
\hline Resíduo & 140 & 12,120 & 10,134 & 0,049 \\
\hline C.V. $(\%)$ & & 15,473 & 12,670 & 20,063 \\
\hline Média Geral (\%) & & 22,500 & 25,125 & 1,104 \\
\hline
\end{tabular}

AL Guarany 2002

\begin{tabular}{lcccc}
\hline \multirow{2}{*}{ Causas da Variação } & \multirow{2}{*}{ GL } & \multicolumn{3}{c}{ Quadrado Médio } \\
\cline { 3 - 5 } & & $\mathbf{1 5}$ dias & Germinação (\%) \\
\cline { 3 - 4 } & 3 & $11335,444^{* *}$ & $13352,239^{* *}$ & $0,118^{*}$ \\
\hline Ambiente & 6 & $982,636^{* *}$ & $1414,117^{* *}$ & $0,044 \mathrm{~ns}$ \\
Horas & 18 & $244,529^{* *}$ & $171,160^{* *}$ & $0,030 \mathrm{~ns}$ \\
Ambiente x Horas & 140 & 12,899 & 13,182 & 0,043 \\
Resíduo & & 16,931 & 14,900 & 19,224 \\
\hline C.V. (\%) & & 21,213 & 24,366 & 1,084 \\
\hline Média Geral (\%) & &
\end{tabular}

* e ** significativos aos níveis de 5 e $1 \%$ de probabilidade pelo test $\mathrm{F}$, respectivamente.

com um decréscimo de viabilidade em função do tempo de armazenamento.

Para a mesma cultivar, foi observado que a interação do ambiente freezer em relação ao número de grãos de pólen germinados não foi significativa aos 15 dias de conservação, o número de micrósporos com emissão de tubo polínico aumentou $(2,86 \%)$ até $3 \mathrm{~h}$ de reativação do metabolismo (Figura 1B). Já, depois de 30 dias de armazenamento, foi possível notar uma tendência de crescimento à medida que aumenta o tempo de descongelamento alcançando $31,29 \%$ de polens germinados em $6 \mathrm{~h}$ de retomada do metabolismo e a porcentagem manteve-se constante até $24 \mathrm{~h}$.

Os grãos de pólen armazenados em freezer apresentam maior porcentagem de germinação que aquele em refrigerador. $\mathrm{O}$ emprego de temperaturas mais baixas normalmente encontra-se ligado à redução do metabolismo do pólen, o que propicia maior longevidade. Resultados semelhantes foram obtidos por
Oliveira et al. (2001) que enfatizam a maior longevidade do pólen congelado de pessegueiro.

$\mathrm{O}$ fato do aparecimento de maior número de polens germinados em 30 dias do que em 15 dias de experimento pode ser explicado por Oliveira et al. (2001), onde enfatizam que a diminuição na porcentagem de polens viáveis pode estar relacionada a vários fatores, tais como as condições de armazenamento, o recipiente usado no acondicionamento do pólen, a manipulação dos recipientes bem como a qualidade da amostra utilizada. A viabilidade do pólen armazenado é mantida se os grãos de pólen estiverem secos (SOUSA, 1988) e conservados em baixas temperaturas (MIRANDA, 1993).

O baixo índice de viabilidade aos 15 dias de armazenamento em freezer também pode ser uma consequência das anormalidades da própria meiose nesta espécie, tais como a presença de univalentes, bivalentes, e alterações como a presença de cromossomos retardatários na placa metafásica e pontes anafásicas, que 
FIGURA 1: Porcentagem de germinação de grãos de pólen de mamoneira da cv. IAC 80 submetidos a horas de descongelamento em 15 dias ( $\boldsymbol{\Delta})$ e 30 dias ( $\mathbf{\square})$ de conservação e diferentes ambientes de armazenamento a baixas temperaturas: (A) Refrigerador; (B) Freezer; (C) Ultrafreezer; (D) Nitrogênio Líquido. Pelotas. UFPel, 2009.

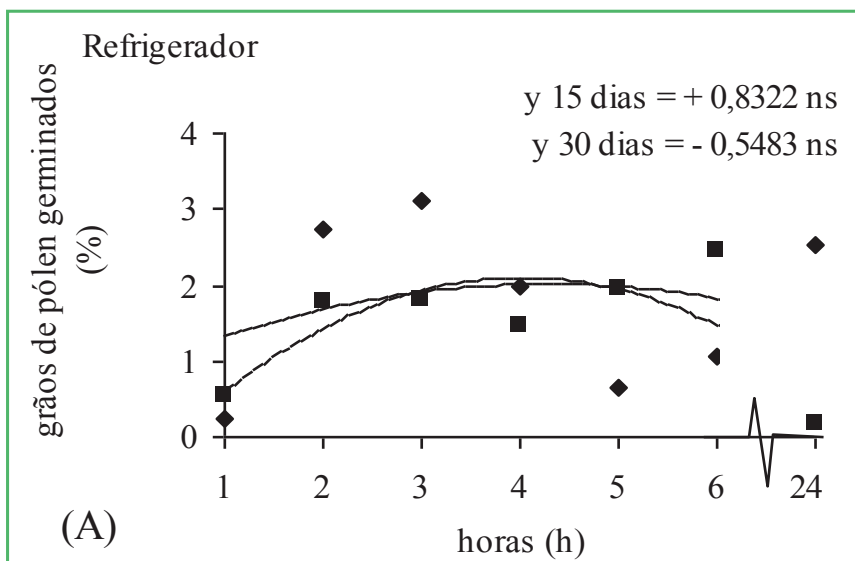

(A)

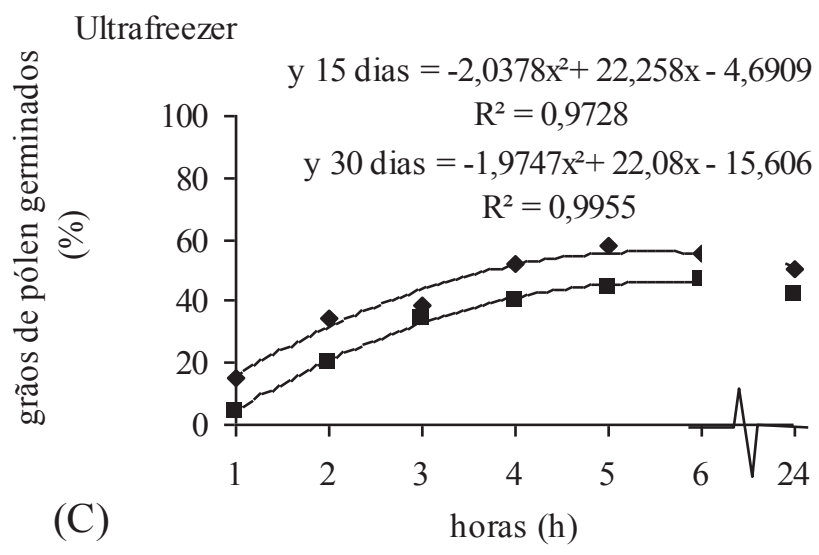

são fatores considerados causadores de grãos de pólen imperfeitos, e consequentemente, inviáveis, ou também esta baixa viabilidade pode ser decorrente da técnica utilizada na análise (VARGAS et al., 2009).

A utilização do ultrafreezer como ambiente de armazenamento demonstrou a manutenção da viabilidade com a emissão de 50\% de tubos polínicos (Figura 1C). Para 15 dias de experimento ocorreu um aumento constante no número de grãos pólen germinados até $5 \mathrm{~h}$ de descongelamento a partir desse horário houve um pequeno decréscimo. Já para 30 dias de armazenamento, ocorreu um atraso na germinação de grãos de pólen em relação a 15 dias onde a emissão do tubo polínico foi crescente até $6 \mathrm{~h}$ de incubação, ou seja, o aumento de tempo de conservação provoca atraso da reativação de processos metabólicos.

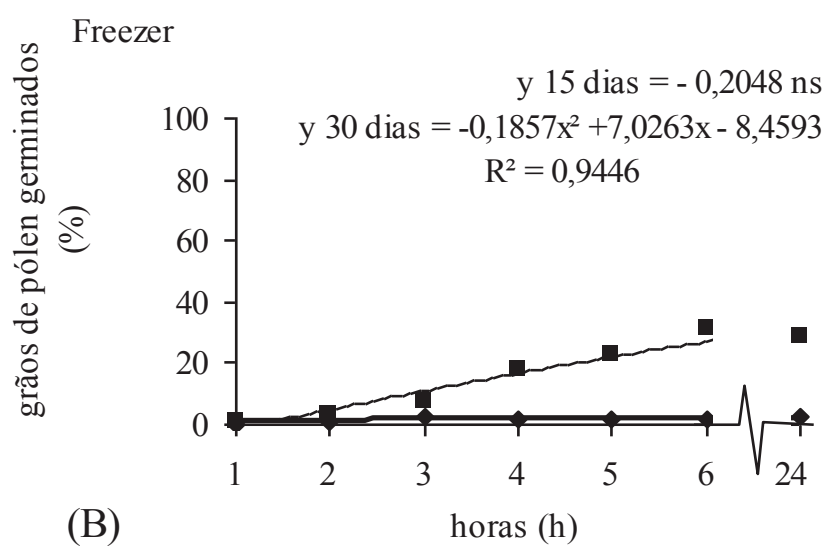

Nitrogênio
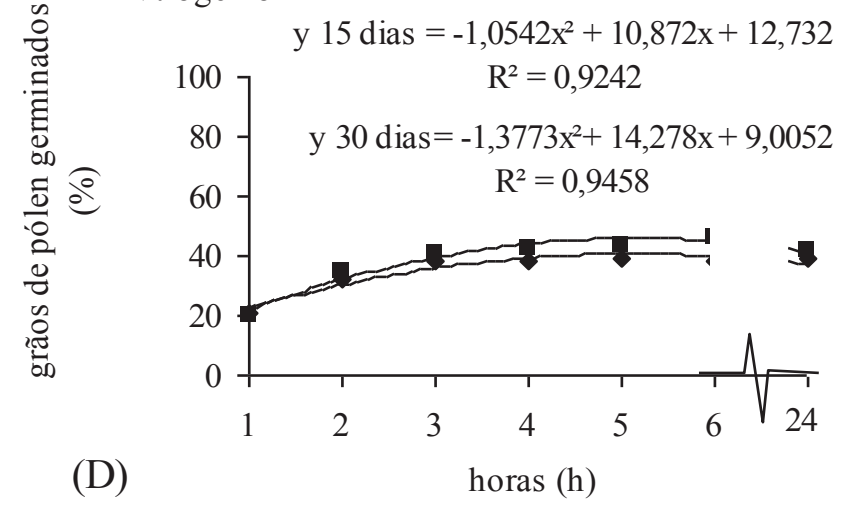

O nitrogênio líquido proporcionou um comportamento semelhante nos dois tempos de armazenamento dessa cultivar com um aumento crescente de grãos de pólen germinados com a elevação do tempo de incubação (Figura 1D). Para 15 dias de conservação o maior porcentual de germinação foi de $39,02 \%$ com 5 h de incubação e para 30 dias de experimento a máxima porcentagem foi de $46,31 \%$ com $6 \mathrm{~h}$ de sucessivas contagens. $\mathrm{O}$ aumento do tempo de incubação promoveu a retomada dos processos fisiológicos representado pelo maior índice germinativo dos grãos de pólen. Esses resultados concordam com Kanazawa et al. (1992), onde alta percentagem de germinação foi verificada para o pólen de espécies do gênero Allium após o armazenamento em nitrogênio líquido por um ano, tendo os autores, sugerido que o 
pólen poderia continuar viável por período superior. A melhor eficiência esperada na preservação à ultra baixa temperaturas está relacionada à maior velocidade de congelamento, que causa menores danos à célula devido a menor desidratação e rompimento das membranas (DUMONT et al., 2004; FELLOWS, 2006).

O refrigerador para a cv. AL Guarany 2002 proporcionou porcentagem inferior a $3 \%$ tendendo a zero com o aumento do tempo nos dois períodos de armazenamento (Figura 2A), valores iguais foram obtidos para a cv. IAC 80. Em 15 dias de conservação, ocorreu um aumento gradativo na porcentagem de grãos de pólen germinados com o incremento das horas, alcançando $2,16 \%$ com 6h de incubação. Já para 30 dias de armazenamento é possível notar que a interação do ambiente refrigerador em relação ao número de grãos de pólen germinados não foi significativa, onde a porcentagem de grãos de pólen germinados não alcançou $1 \%$.
A baixa temperatura é a principal variável que afeta a qualidade fisiológica dos grãos de pólen retardando a durabilidade dos mesmos pela diminuição dos processos metabólicos que necessitam de energia térmica para ocorrer. Além do mais, Visser (1955) relatou que a longevidade dos grãos de pólen armazenados depende da diminuição da atividade fisiológica pela redução da taxa respiratória, diminuição do metabolismo, redução da taxa de degradação celular e impedimento da germinação prematura e, consequente proliferação de microorganismos e deterioração dos grãos de pólen (DAVIDE et al., 2009). Nesse experimento utilizando o refrigerador como ambiente de armazenamento, os grãos de pólen das cultivares de mamoneira utilizadas não sobreviveram a 15 dias de conservação por esta temperatura não propiciar o ambiente adequado de conservação.

FIGURA 2: Porcentagem de germinação de grãos de pólen de mamoneira da cv. AL Guarany 2002 submetidos a horas de descongelamento em 15 dias ( $\boldsymbol{\Delta})$ e 30 dias $(\boldsymbol{\square})$ de conservação e diferentes ambientes de armazenamento à baixas temperaturas: (A) Refrigerador; (B) Freezer; (C) Ultrafreezer; (D) Nitrogênio Líquido. Pelotas. UFPel, 2009.

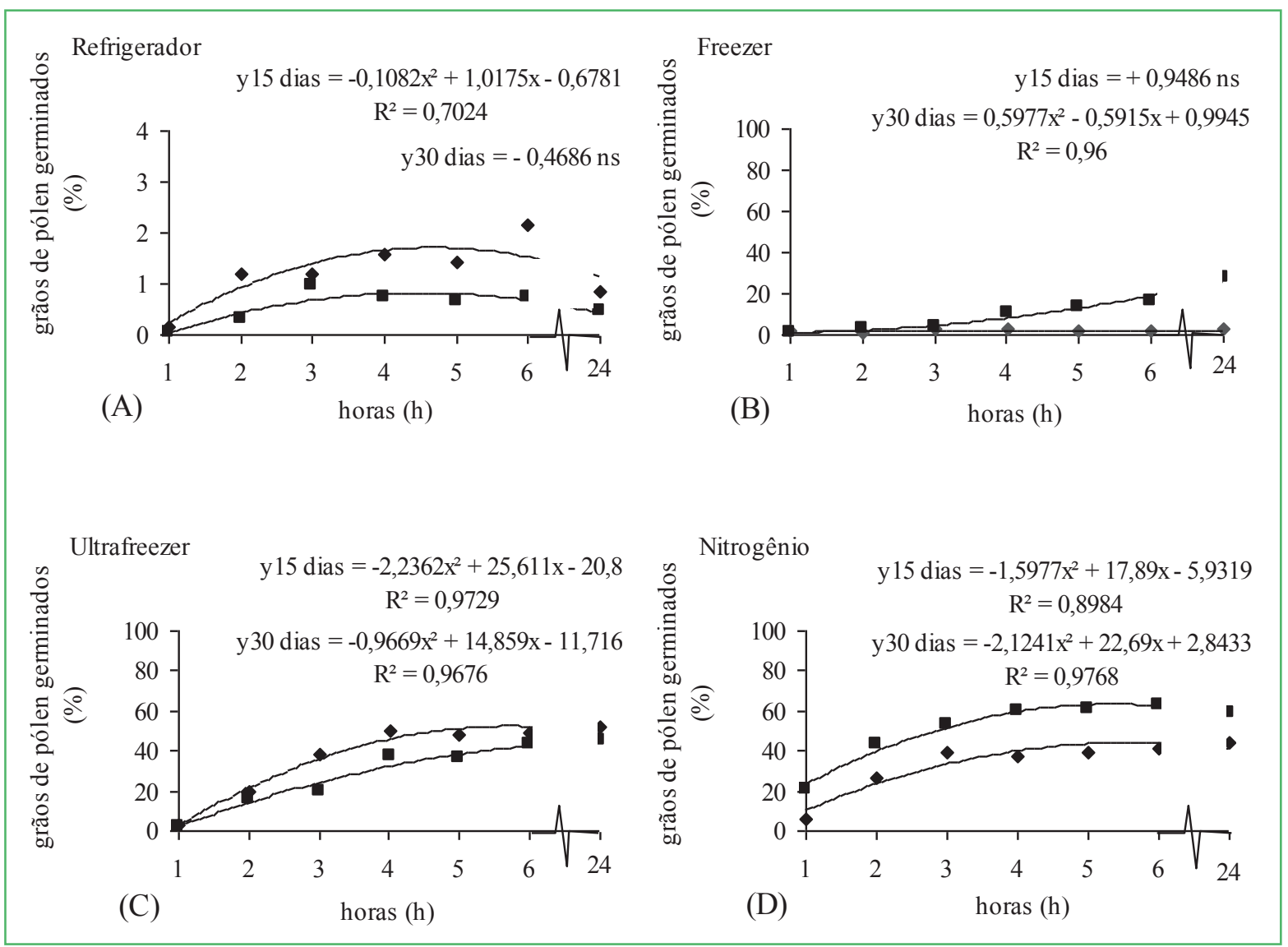


Utilizando-se o freezer como ambiente de armazenamento (Figura 2B), foi possível constatar resposta semelhante ao descrito anteriormente para a cv. IAC 80 , onde a germinação in vitro de polens armazenados durante 30 dias foi maior que os polens armazenados durante 15 dias. Esse problema pode ser explicado pela qualidade da amostra, manipulação do material ou da técnica utilizada para análise. Para 15 dias de experimento, resultados não significativos foram observados. No entanto, para 30 dias de conservação, ocorreu um aumento gradativo na porcentagem de grãos de pólen germinados com o incremento das horas de descongelamento até $24 \mathrm{~h}$ do inicio do período de incubação, com $27,83 \%$ de tubos polínicos emitidos.

Após um período de $24 \mathrm{~h}$ de incubação, observouse à liberação de exsudado pelo grão de pólen. Em cultivares de maracujazeiro o pólen parece ser pegajoso, por ser recoberto por uma substância chamada pollenkit que, dentre outras funções, atua como protetor, minimizando a desidratação e consequentemente a perda de viabilidade nesta espécie (SOUZA et al., 2002). Nas cultivares de mamoneira, foi observado a liberação de substância que parece exercer o mesmo papel. Resultados semelhantes em mamoneira foram encontrados por Vargas et al. (2009).

Para a mesma cultivar, na conservação em ultrafreezer (Figura 2C) ocorreu um comportamento semelhante nos dois períodos de armazenamento, porém os grãos de pólen com 15 dias de armazenamento apresentaram maior porcentagem de germinação in vitro que aqueles com 30 dias. A retomada dos processos metabólicos ocorreu com $24 \mathrm{~h}$ de incubação onde foi visualizada a estabilidade do número de grãos de pólen germinados, no qual para 15 dias de armazenamento foram contados $51,67 \%$ de emissão de tubos polínicos e para 30 dias foram analisados $44,81 \%$.

No ambiente de armazenamento nitrogênio líquido, observou-se comportamento similar nos dois tempos de conservação, ocorrendo um aumento crescente de grãos de pólen germinados com o aumento do tempo de incubação (Figura 2D). Como visto para a cv. IAC 80 no mesmo ambiente de armazenamento ocorreu uma porcentagem maior de grãos de pólen germinados em 30 dias de armazenamento do que em 15 dias. Porém para 15 dias de armazenamento foram necessárias $24 \mathrm{~h}$ de incubação para serem alcançados $44,48 \%$ de germinação in vitro, já para 30 dias foram $6 \mathrm{~h}$ para se alcançar $62,51 \%$ de grãos de pólen com emissão de tubos polínicos.

Os resultados obtidos da conservação em nitrogênio líquido evidenciaram a necessidade de estudos complementares da técnica utilizada e dos problemas observados. Apesar da criopreservação ter sido testada preliminarmente em diversas espécies, ainda não existe uma rotina de laboratório que possa garantir a conservação de germoplasma vegetal. Isto se deve à complexidade, tanto técnica como biológica, que envolve os processos de congelamento e descongelamento de grãos de polens. Além disso, diferentes espécies reagem de maneira diversa a criopreservação, de forma que se torna necessário o desenvolvimento de metodologias que atendam as exigências de cada espécie (WILLIAMS, 1990).

Para o experimento realizado aos 60 dias de conservação do material biológico, a análise de variância mostrou que houve diferença estatística significativa somente para o fator ambiente de armazenamento $(\mathrm{p}<0,05)$ apresentando porcentagem de germinação inferior $(<1 \%)$ a aquelas encontradas aos 15 e 30 dias de armazenamento. Para a cv. IAC 80 (Figura 3A), houve diferença estatística do freezer em relação aos demais ambientes de conservação, estes apresentando uma porcentagem maior de grãos de pólen germinados. Já para a cv. AL Guarany 2002 (Figura 3B) respostas diversificadas foram observadas, onde o nitrogênio líquido apresentou maior porcentagem de germinação, este não diferindo do freezer, mas diferindo dos demais ambientes estudados. Em geral, as cultivares estudadas apresentaram comportamento semelhante aos 60 dias de armazenamento, mostrando drástica redução na viabilidade polínica em todos os ambientes analisados. De acordo com Baéz et al. (2002), Gibernau et al. (2003) e Khan e Perveen (2006), em grãos de pólen armazenados não se observa aumento de viabilidade polínica com o passar do período de armazenamento, mas sim decréscimo. 
FIGURA 3: Porcentagem de germinação de grãos de pólen de mamoneira das cvs. IAC 80 (A) e AL Guarany 2002 (B) submetidas a diferentes ambientes de armazenamento em baixas temperaturas avaliada aos 60 dias de conservação. Pelotas. UFPel, 2009.

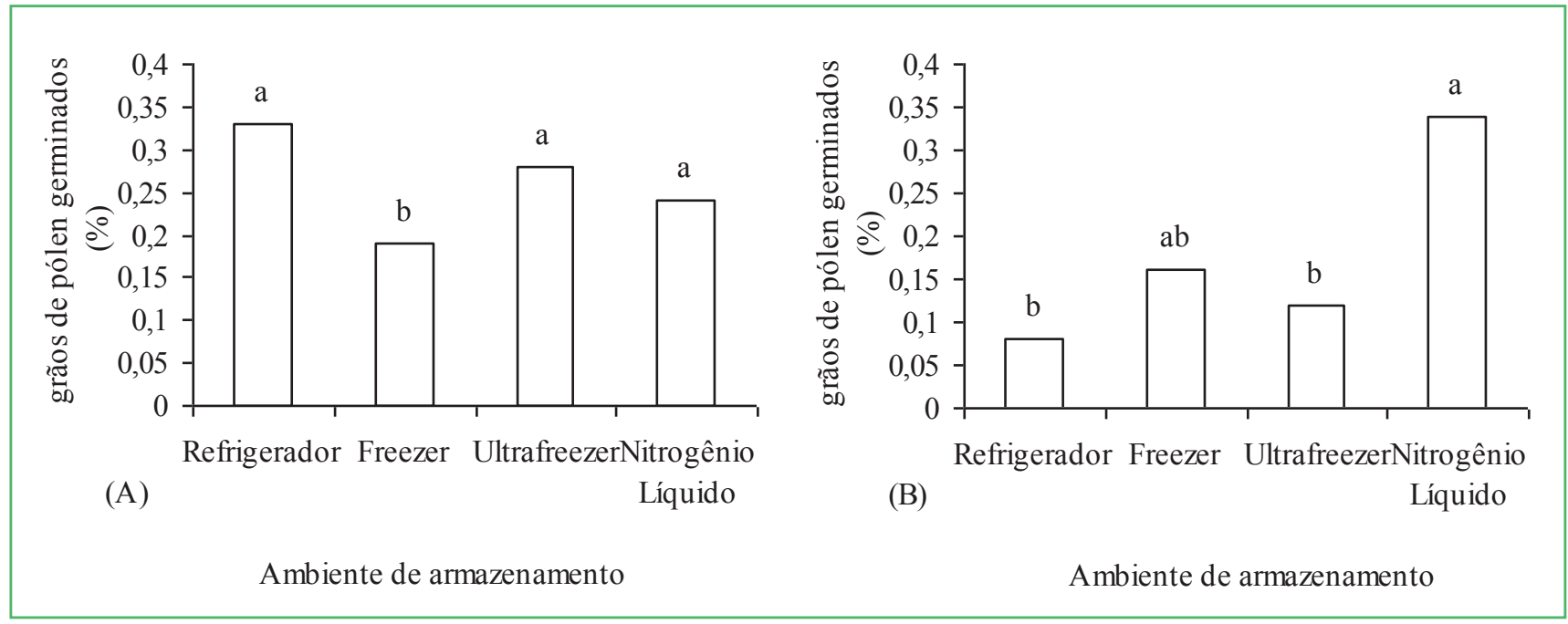

A inviabilidade polínica pode ser resultante do armazenamento, como também pode ocorrer durante a microsporogênese, em que falhas no comportamento meiótico resultam em gametas com cromossomos desbalanceados ou anucleados, ou ainda durante a microgametogênese, resultando em grãos de pólen com citoplasma retraído (TWELL, 1995). A interferência do efeito do ambiente no comportamento meiótico, e consequentemente na viabilidade dos grãos de pólen, foi observada em Bougainvillea sp., quando foram comparadas variedades de várias regiões do Brasil (ADAMOWSKI et al., 1996).

No entanto, foi possível verificar que o ambiente de ultrafreezer pode ser utilizado com sucesso para armazenamento de grãos de pólen de mamoneira. No entanto, a cv. IAC 80 apresentou a necessidade de 5 e $6 \mathrm{~h}$ de incubação para a retomada do metabolismo de grãos de pólen em 15 e 30 dias de armazenamento, respectivamente. E, para a retomada dos processos metabólicos da cv. AL Guarany 2002, em 15 dias de conservação foram necessárias $24 \mathrm{~h}$ de incubação e para 30 dias foram necessárias $6 \mathrm{~h}$ de incubação.

Apesar das cultivares terem exibido taxas de viabilidade variáveis nos períodos de conservação, é possível considerar que os resultados obtidos para o pólen possam subsidiar programas de melhoramento em mamoneira, viabilizando cruzamentos entre indivíduos com potencial econômico que apresentem barreiras temporais de floração, ou estejam geograficamente separados (PIO et al., 2007). Portanto, os resultados mencionados no presente trabalho estão de acordo com a literatura, ou seja, com o passar do tempo observou-se redução significativa da viabilidade dos grãos de pólen armazenados.

\section{Referências}

ACAR, I.; KAKANI, V. G. V. The effects of temperature on in vitro pollen germination and pollen tube growth of Pistacia spp. Scientia Horticulturae, Amsterdam, v. 125, p. 569-572, 2010.

ADAMOWSKI, E. V.; PAGLIARINI, M. S.; VALVA, F. D. Avaliação do comportamento meiótico em Bougainvillea sp. (Nyctaginaceae) de diferentes regiões do Brasil. Revista Unimar, Marília, v. 18, p. 403-412, 1996.

BAÉZ, P.; RIVEROS, M.; LEHNEBACH, C. Viability and longevity of pollen of Nothofagus species in south Chile. New Zealand Journal of Botany, Wellington, v. 40, p. 671- 678, 2002.

BELTRÃO, N. E. de M. Informações sobre o biodiesel, em especial feito com o óleo de mamona. Campina Grande: EMBRAPA-CNPA, 2003. 3 p. (Comunicado técnico 177).

DANNER, M. A.; CITADIN, I.; SASSO, S. A. Z.; SACHET, M. R.; MALAGI, G. Modo de reprodução e viabilidade de pólen de três espécies de jabuticabeira. Revista Brasileira de Fruticultura, Jaboticabal, v. 33, n. 2, 2011.

DAVIDE, L. M. C.; PEREIRA, R. C.; ABREU, G. B.; SOUZA, J. C.; PINHO, E. V. R. V. Viabilidade de pólen de milho em diferentes períodos de armazenamento em baixa temperatura. Revista Brasileira de Milho e Sorgo, Sete Lagoas, v. 8, n. 2, p. 199-206, 2009. 
DUMONT, F.; MARECHAL, P.; GERVAIS, P. Cell size and water permeability as determining factors for cell viability after freezing at different cooling rates. Applied and Environmental Microbiology, Washington, v. 70, p. 268-272, 2004.

FELLOWS, P. J. Tecnologia do processamento de alimentos: princípios e prática. Porto Alegre: Artmed, 2006. 602 p.

GIBERNAU, M.; MARQUART, D.; DIAZ, A. Pollen viability and longevity in two species of Arum. Aroideana, Miami, v. 26, p. 5862, 2003.

GOMES, P. R.; RASEIRA, M. C.; BAUDET, L. L.; PESKE, S. T. Armazenamento do grão de pólen de cebola (Allium cepa L.). Revista Brasileira de Sementes, Brasília, v. 25, n. 1, p 14-17, 2003.

GOMEZ, P.; GRADZIEL, T. M.; ORTEGA, E.; DICENTA, F. Short term storage of almond pollen. HortScience, Alexandria, v. 35, n. 6, p. 151-152, 2000.

KAKANI, V. G.; REDDY, K. R.; KOTI, S.; WALLACE, T. P.; PRASAD, P. V. V.; REDDY, V. R.; ZHAO, D. Differences in in vitro pollen germination and pollen tube growth of cotton cultivars in response to high temperature. Annals of Botany, Oxford, v. 96, n. 1, p. 59-67, 2005.

KANAZAWA, T.; KOBAYASHI, S.; YAKUWA, T. Flowering process, germination and storage of pollen in Allium victorialis L. spp. platyphyllum Hult. Journal of the Japanese Society for Horticultural Science, Kyoto, v. 60, n. 4, p. 947-953, 1992.

KARTHA, K. K. Meristem culture and germplasm preservation. In: KARTHA, K. K. (Ed.). Cryopresevation of plant cells and organs. Boca Roton: CRS Press, 1985. p. 115-134.

KHAN, S. A.; PERVEEN, A. Germination capactity of stored pollen of Abelmoschus esculentus L. (Malvaceae) and their maintenance. Pakistan Journal of Botany, Karachi, v. 38, p. 233-236, 2006.

MIRANDA, I. P. A. A importância da conservação in vitro do pólen da pupunheira (Bactris gasipaes Kunth) Arecaceae para o melhoramento genético. In: FERREIRA, E. J. G; SANTOS, G. M.; LEÃO, E. L. M.; OLIVEIRA, L. A. (Ed.). Bases científicas para estratégias de preservação e desenvolvimento da Amazônia. v. 2. Manaus: SCT/INPA, 1993. p. 361-171.

OLIVEIRA, M. S. P.; MAUÉS, M. M.; KALUME, M. A. A. Viabilidade de pólen in vivo e in vitro em genótipos de açaizeiro. Acta Botânica Brasílica, São Paulo, v. 15. n. 1, p. 27-33, 2001.

PASQUAL, M.; PETRI, J. L.; MATOS, C. S. Polinização da macieira III: cultivares BR-1 e Mollies Delicious. Pesquisa Agropecuária Brasileira, Brasília, v. 17, n. 10, p. 1477-1481, 1982.

PIO, L. A. S.; RAMOS, J. D.; PASQUAL, M.; JUNQUEIRA, K. P.; SANTOS, F. C.; RUFINI, J. C. M. Viabilidade do pólen de laranjas doces em diferentes condições de armazenamento. Ciência e Agrotecnologia, Lavras, v. 31, n. 1, 2007.
SANTOS, I. R. I. Criopreservação: potencial e perspectivas para a conservação de germoplasma vegetal. Revista Brasileira de Fisiologia Vegetal, Campinas, v. 12, p. 70-84, 2000.

SAVY FILHO, A.; BANZATTO, N. V.; BARBOZA, M. Z. Mamona. In: Oleaginosas no Estado de São Paulo: análise e diagnóstico. Campinas (SP): Coordenadoria de Assistência Técnica Integral, 1999. p. 29-39.

SIREGAR, I. Z.; SWEET, G. B. The impact of extraction and storage conditions on the viability of radiata pine pollen. Silvae Genetica, Bogor, v.4 9, n. 1, p. 10-14, 2000.

SOUSA, V. A. Criopreservação de pólen de Eucalyptus spp. Boletim de Pesquisa Florestal, Colombo, n. 21, p. 15-19, dez. 1990.

SOUSA, V. A. Manejo e viabilidade do pólen de Eucalyptus. 1988. 155 f. Dissertação (Mestrado em Agronomia, Área de concentração em Engenharia Florestal) - Escola Superior de Agricultura "Luiz de Queiroz”, Universidade de São Paulo, Piracicaba, 1988.

SOUSA, V. A.; SCHEMBERG, E. A.; AGUIAR, A. V. Germinação in vitro do pólen de jerivá (Syagrus romanzoffiana (S.) Cham). Scientia Forestalis, Piracicaba, v. 38, n. 86, p. 147-151, 2010.

SOUZA, M. M.; PEREIRA, T. N. S.; MARTINS, E. R. Microsporogênese e microgametogênese associadas ao tamanho do botão floral e da antera e viabilidade polínica em maracujazeiroamarelo (Passiflora edulis Sims $f$. flavicarpa degener). Ciência e Agrotecnologia, Lavras, v. 26, n. 6, p. 1209-1217, 2002.

TWELL, D. Diphtheria toxin-mediated cell ablation in developing pollen: vegetative cell ablation blocks generative cell migration. Protoplasma, New York, v. 187, p. 144-154, 1995.

VARGAS, D. P.; SOUZA, S. A. M.; ANJOS E SILVA, S. D.; BOBROWSKI, V. L. Análise dos grãos de pólen de diferentes cultivares de mamona (Ricinus communis L., EUPHORBIACEAE): conservação e viabilidade. Arquivo do Instituto Biológico, São Paulo, v. 76, n. 1, p. 115-120, 2009.

VISSER, T. Germination and storage of pollen. Meded Landbouhogesch, Wageningen, v. 55, p. 1-68, 1955.

WILLIAMS, J. T. Germplasm conservation in vitro and cryopreservation. In: TORRES, A. C.; CALDAS, L. S. (Ed.). Técnicas e aplicação da cultura de tecidos de planta. Brasília: ABCTP/EMBRAPA/CNPH, 1990. p. 267-286.

ZONTA, E. P.; MACHADO, A. A. SANEST - Sistema de análise estatística para microcomputadores. Pelotas: Universidade Federal de Pelotas, 1984. 138 p. 